\title{
Processo de Avaliação de uma Galeria Virtual de Artes como Recurso para a Educação Estética
}

\section{Proceso de Evaluación de una Galería Virtual de Artes Como Recurso Para La Educación Estética}

\author{
Evaluation Process of a Virtual Art Gallery as a Resource for Aesthetic Education
}

\author{
Rogério Augusto Bordini \\ José Eduardo Ribeiro de Paiva \\ Universidade Estadual de Campinas (UNICAMP), Instituto de Artes, Campinas/SP - Brasil
}

RESUMO

Espaços museais e artísticos desempenham, sobretudo, um papel comunicacional na sociedade: comunicar a cultura, a história, a arte, a obra, identidades que são preservadas pelas redomas de museus e galerias que têm a educação cultural, histórica e estética como principal fim ao seus visitantes. Com o surgimento dos museus virtuais, a experiência dos visitantes passou a ser facilitada, complementada e potencializada pelos meios tecnológicos, permitindo o acesso a uma diversidade de acervos e conteúdos culturais. Esse trabalho tem como objetivo promover um breve relato sobre o processo de avaliação do GAIA Virtual, uma galeria de artes tridimensional desenvolvida para os formatos Web e em realidade virtual. Além de apresentar as principais motivações do projeto, será discutido as impressões dos participantes ao testarem o recurso e suas potencialidades como tecnologia digital para a educação artística.

Palavras chave: Galerias de Arte, Tecnologias Digitais, Realidade Virtual, Educação RESUMEN

Los espacios museales y artísticos tienen, sobre todo, un papel comunicacional en la sociedad: comunicando cultura, historia, arte, obras, identidades que se conservan en la cúpula de museos y galerías que tienen la educación cultural, histórica y estética como principal fin a sus visitantes. Con la aparición de los museos virtuales, la experiencia de los visitantes se ha visto facilitada, complementada y mejorada por medios tecnológicos, permitiendo el acceso a una diversidad de colecciones y contenidos culturales. Este trabajo tiene como objetivo proporcionar una breve reseña del proceso de evaluación de GAIA Virtual, una galería de arte tridimensional desarrollada para formatos web y de realidad virtual. Además de presentar las principales motivaciones del proyecto, se discutirán las impresiones de los participantes de probar el recurso y su potencial como tecnología digital para la educación artística.

Palabras clave: Galerías de Arte, Tecnologías Digitales, Realidad Virtual, Educación 


\section{ABSTRACT}

Museum and artistic spaces, above all, play a communicational role in society: communicating culture, history, art, work and identities that are preserved by the domes of museums and galleries that have cultural, historical and aesthetic education as their main mission. With the emergence of virtual museums, the experience of visitors has been facilitated, complemented and enhanced by technological means, allowing access to a diversity of cultural collections and contents. This paper aims to provide a brief report of the evaluation process of GAIA Virtual, a three-dimensional art gallery developed for Web and Virtual Reality formats. In addition to presenting the main motivations of the project, participants' impressions of testing the resource and its potential as a digital technology for arts education will be discussed.

Keywords: Art Galleries, Digital Technologies, Virtual Reality, Education

\section{1 - Introdução}

A partir da década de 1990, nasce um novo conceito de museu decorrente do surgimento de uma sociedade transformada pelos avanços das tecnologias informacionais (Llussà, 2002). Os museus virtuais - assim como as galerias e outros espaços expositivos - são entidades digitais que se baseiam nas características de museus tradicionais, com capacidade de complementar, registrar e/ou aumentar a experiência da visitação por meio da personalização, interatividade e fácil acesso aos conteúdos com apresentação coerente e sistemática (Panciroli et al., 2017). Por meio de dispositivos conectados à Internet, pessoas em qualquer lugar do mundo podem facilmente ter acesso à uma diversidade de acervos reais disponibilizados digitalmente (como coleções artísticas, arqueológicas, naturais, científicas, etc). Tal experiência pode ser ainda potencializada por meio de: mídias que utilizam diferentes códigos expressivos (imagens, textos, vídeos, sons, animações); possibilidades de interação que aprimoram o senso de agência do usuário, oferecendo-o a possibilidade de selecionar e estruturar ativamente uma variedade de caminhos; conexão a uma rede que favorece o acesso a um ou mais museus e usuários; e, por fim, a possibilidade de acesso a pessoas portadoras de imparidades auditivas, visuais e/ou físicas que podem apresentar dificuldades de deslocamento até um museu e na apreciação de seus conteúdos.

\section{2 - Museus e Galerias Virtuais como Espaços para Aprendizagem Artística}

Prensky (2012) destaca as mudanças no estilo cognitivo da atual geração de aprendizes que nasceu na era das tecnologias digitais, em um mundo altamente conectado com acesso fácil, rápido a informações e pessoas os denominados nativos digitais. O autor observa a necessidade de se rever as teorias e práticas pedagógicas para que estejam mais adequadas a esses novos estilos de aprendizagem, e defende que essas práticas sejam baseadas no uso crescente de tecnologias digitais justamente por estarem alinhadas com as necessidades e os estilos de aprendizagem da geração atual e futura.

Por outro lado, Hernández (2000) aponta as dificuldades que professores podem enfrentar - sobretudo os de Artes - ao lidarem com a sensibilização crítica dos alunos em uma cultura informatizada que a cada novo dia invade nossas casas com imagens que mascaram a realidade. Richter (2003) fala sobre a educação estética de aprendizes como modo de oferecê-los a sensibilização do olhar para apreciação dos meios nos quais estão inseridos, como forma de compreensão cultural e antropológica,

O ensino da arte na escola precisa preservar essa linha do universo estético das crianças, para poder não somente contextualizar o ensino da arte em si, mas também contextualizá-lo em relação ao meio cultural e estético em que as crianças estão inseridas. Para tanto é preciso aplicar o conceito de arte, adotando uma antropológica de cultura, na tentativa de encontrar caminhos para a realização e uma experiência de ensino das artes visuais com caráter de pós-modernidade (...) (p. 54).

Nesse sentido, museus virtuais revelam-se como recursos digitais capazes de auxiliar o professor em trabalhos artístico-pedagógicos para a educação estética de seus alunos a partir de vivências em tais espaços. Serviços como Google Art Project e Artsteps1 permitem que alunos construam seus próprios catálogos de exposições de estilos e artistas que mais lhe chamam a atenção ou, mediante 
uma proposta combinada pelo professor, tal ferramenta pode ser usada como meio de pesquisa e exploração de espaços de exposição em busca de determinadas obras, artistas, artefatos, estilos, materiais, etc., colocando o aluno no papel ativo de um investigador. Ademais tais tecnologias ainda revelam-se como recursos eficazes para permitir a acessibilidade de diversos conteúdos artísticos, desde que projetados e desenvolvidos em conformidade com o conjunto de regras que atendam diversos públicos e se aproximem dos princípios do Design Universal (Goldsmith, 1963), assim como defendido pelo World Wide Web Consortium (W3C, 2008).

\section{3 - GAIA Virtual}

GAIA Virtual trata-se de um modelo tridimensional e digital da Galeria de Artes do Instituto de Artes (GAIA) da Universidade Estadual de Campinas (UNICAMP) (Fig. 1), cuja versão virtual permite que as obras expostas sejam visualizadas por meio do próprio website da instituição2, tanto nas versões Web quanto em Realidade Virtual (RV). A proposta do projeto, desenvolvido entre 2018 e 2019, também teve como motivação criar um espaço virtual gratuito de colaboração e compartilhamento entre
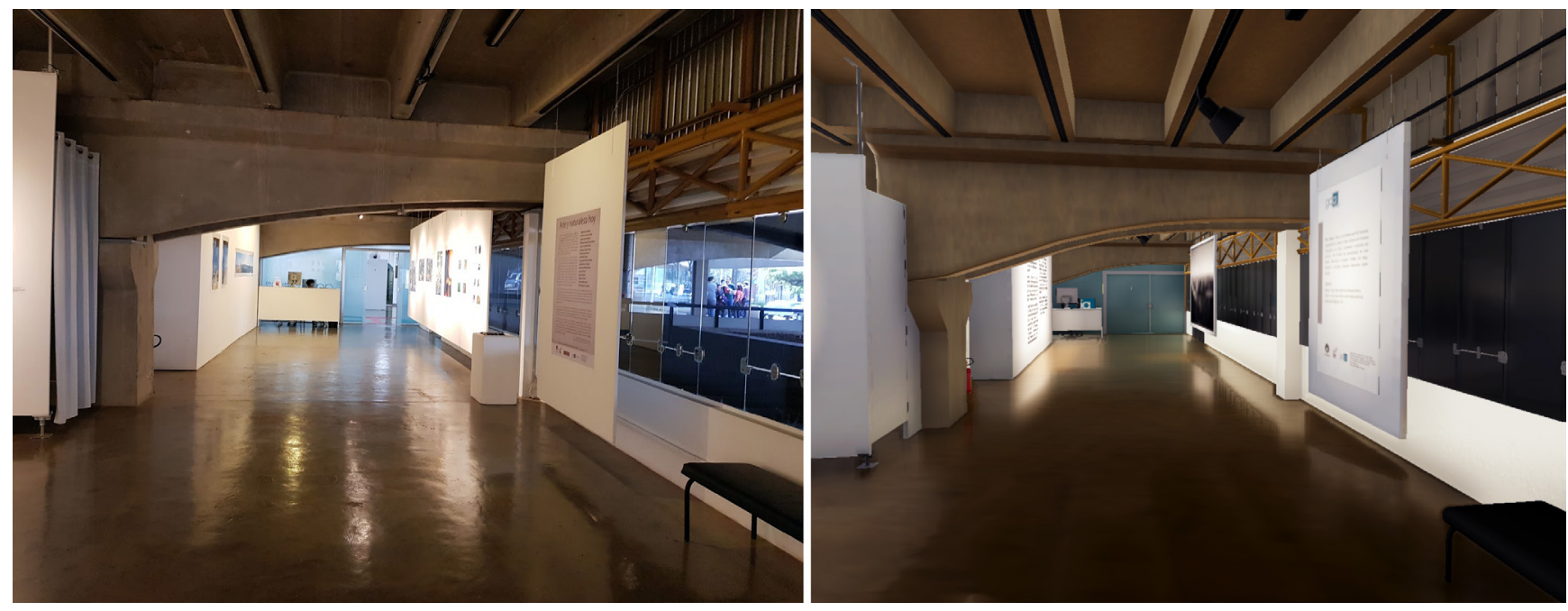

artistas, educadores, estudantes e entusiastas, os quais poderão realizar exposições e visitas virtuais independentemente de suas localizações no Brasil ou no mundo.

Figura 1 - Espaço físico da GAIA à esquerda e sua versão digital à direita Fonte: acervo pessoal

A criação da GAIA Virtual se deu por meio do software 3DS Max3 que permitiu a reconstrução fiel da galeria a partir das plantas originais do salão com descrições detalhadas acerca das medidas das áreas expositivas, posicionamento das luzes e das folhas de MDF que sustentam as obras. O projeto compilado foi importado ao Unity 54 , software de desenvolvimento de jogos eletrônicos em 2D e 3D que permitiu a aplicação e manipulação de materiais, cores, luzes e mecânicas de interação no espaço virtual a partir de sistemas de arraste-e-solta e programação em JavaScript ou C\#.

\section{4 - Processo de Avaliação e Potencialidades Educacionais}

A avaliação da GAIA Virtual ocorreu por meio de testes de usabilidade com 15 participantes de diferentes perfis, como estudantes de artes, professores da UNICAMP, funcionários da GAIA e pessoas que não possuem contato com arte e/ ou costume de visitar galerias e museus. Um formulário online em forma de convite com descrição detalhada da pesquisa e de todos os procedimentos para coleta de dados foi enviado aos alunos da universidade. Os testes foram realizados na própria instituição e ocorreram em duas etapas consecutivas: 1) Etapa Web - Não-imersivo (15 minutos), interação com a versão Web por meio de notebook com headphones; 2) Etapa RV - Imersivo (15 minutos), visita ao mesmo espaço virtual usando headset de realidade virtual. Após cada interação, os participantes responderam a 
Figura 2 - Satisfação geral dos participantes em relação à GAIA Virtual Fonte: acervo pessoal um questionário com perguntas em escala Likert de cinco pontos que avaliaram a experiência estética (percepção das obras, senso de presença etc.) e a usabilidade da aplicação (consistência dos controles, interface intuitiva etc.).

\section{5 - Conclusão}

De modo geral, os participantes se demonstraram satisfeitos com a experiência vivenciada com ambas as versões da GAIA Virtual (Fig. 2), e muitos relataram que o sistema pode funcionar como um eficaz recurso educacional e acessível, sobretudo no que diz respeito a despertar o interesse em pessoas que não costumam visitar exposições artísticas e/ou que não podem acessá-las.
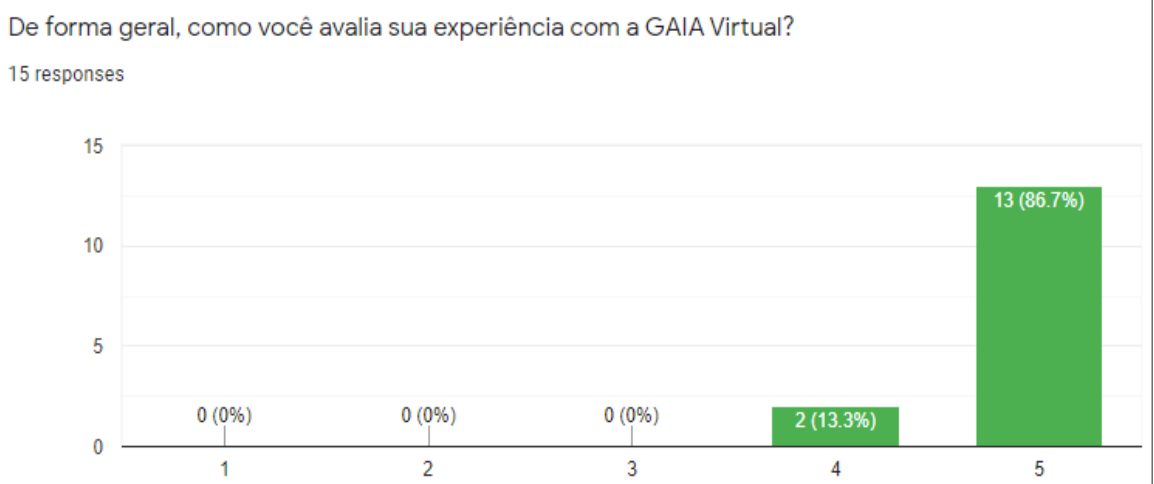

Poder caminhar por um espaço artístico tridimensional, oferecer dicas perceptuais mais ricas e feedback multimodal (ex: visualizar objetos 3D de vários pontos de vista ou ampliar/reduzi-los), nos dá indícios de que os visitantes podem aumentar seus processos de raciocínio e, consequentemente, podem se tornarem mais interessados em conteúdos artísticos (Katz \& Halpern, 2015). Como próximos passos, alguns ajustes levantados nos testes serão realizados numa próxima versão, como aprimorar a interface gráfica (ex: fontes maiores, cores mais discretas, etc), melhoria gráfica na versão RV e inserção de instruções em áudio para que deficientes visuais também possam visitar o espaço virtual.

\section{6 - Referências}

Goldsmith, S (1963). Designing for the Disabled: A Manual of Technical Information. Architectural Association (Great Britain). School of Architecture. Royal Institute of British Architects, Technical Information Service.

Katz, J. \& Halpern, D. (2015). Can Virtual Museums Motivate Students? Towards a Constructivist Learning Approach. Journal of Science Education and Technology. 24. DOI:10.1007/s10956-015-9563-7.

Llussà, X. (2002) O design do museu na sociedade da informação. Publicação do Ciberpesquisa. Centro de Estudos e Pesquisas em Cibercultura do Curso de Pós Graduação da Faculdade de Comunicação da Universidade Federal da Bahia, ano 2, v.1, n. 17. Salvador.

Panciroli, C; Russo, V \& Macauda, A. (2017). When Technology Meets Art: Museum Paths between Real and Virtual. Proceedings of International and Interdisciplinary Conference IMMAGINI?. Brixen, Italy.

Prensky, M. Aprendizagem baseada em jogos digitais. São Paulo: Editora Senac São Paulo.

Richter, I. M. (2003). Interculturalidade e estética do cotidiano no ensino das Artes Visuais. Campinas: Mercado das Letras.

World Wide Web Consortium - W3C. (2008). Web Content Accessibility Guidelines (WCAG) 2.0. Retrieved June 2, 2020 from: https://www.w3.org/TR/WCAG20/ 